\title{
CORROSION IN ACIDIC BEVERAGES AND RECOVERY OF MICROHARDNESS OF HUMAN TEETH ENAMEL
}

\author{
P. GAALOVÁ*, D. GALUSKOVÁ*, J. KOVÁČ**, D. KOVÁČ**, "D. GALUSEK* \\ *Vitrum Laugaricio - Joint Glass Center of the Institute of Inorganic Chemistry, SAS, Alexander Dubček University of Trenčin, \\ and Faculty of Chemical and Food Technology, Slovak University of Technology, Študentská 2, 91150 Trenčin, Slovakia \\ **Faculty of Medicine, Comenius University of Bratislava, Vajanského nábrežie, 81102 Bratislava, Slovakia \\ "E-mail: dusan.galusek@tnuni.sk
}

Submitted October 31, 2016; accepted February 9, 2016

\begin{abstract}
Keywords: Human tooth enamel, Microhardness, Corrosion, Recovery
We studied the influence of corrosion in acidic beverages (white wine, $p H \sim 3.5$ ) on micromechanical properties of human

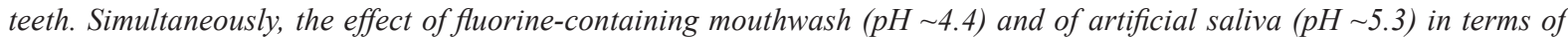
their protective action against corrosion, and the recovery of mechanical properties through fluoridation and re-calcification was studied. The influence of the solutions on Vickers hardness of dental enamel was monitored on the basis of results from the corrosion tests carried out under quasi-dynamic conditions. The tests were performed at the temperature corresponding to the temperature of human body $\left(37^{\circ} \mathrm{C}\right)$. The measurements confirmed a significant deterioration of microhardness with prolonged exposure to white wine. The Vickers hardness decreased from 347 HV0.2 in un-corroded specimens to 186 HV0.2 in samples corroded for 60 minutes in white wine. A recovery of Vickers hardness was observed after 60 minutes exposition time in the fluoridation solution, with the increase from 186 to 372 HV0.2. Similar effect was observed in the artificial saliva solution, with observed hardness increase from 186 to 320 HV0.2. Healing of corrosion-induced defects by the action of both solutions was observed by SEM, and associated with observed increase of hardness.
\end{abstract}

\section{INTRODUCTION}

Teeth corrosion is multifactorial negative phenomenon, comprising mutual action of chemical, biological and behavioural factors, resulting in removal of minerals from the teeth surface $[1,2]$. Dental corrosion may be caused by intrinsic or extrinsic agents. Intrinsic corrosion is associated with gastric acid, which may be present intra-orally following vomiting and gastroesophageal reflux [3]. Excessive consumption of acidic food and beverages are one of the most common extrinsic factors that cause dental corrosion $[4,5]$. Chemical corrosive potential of corrosion components, e.g. acid drinks, depends from chemical factors such as $\mathrm{pH}$, titration acidity $[1,6]$, content of minerals, cleanliness of teeth surfaces and chelation properties of calcium [7-9]. The $\mathrm{pH}$ value, content of calcium, phosphorus and fluorides in drinks determine the degree of saturation, while the driving force depends from the content of minerals [10]. The contents of calcium and phosphorus in beverages are therefore important factors of the corrosive potential, because they are responsible for concentration gradient between the tooth and the corrosion environment.

Various acids, such as tartaric acid, malic acid, lactic acid, ascorbic acid, citric acid and phosphoric acid, which are a common component of beverages, including wine, have a strong destructive effect on the surface of teeth [11-13]. The teeth corrosion in alcoholic beverages, such as wine, is especially a problem of sommeliers, who can taste as many as 200 wines a week. During tasting they hold wine in mouth for longer period of time, which is sufficient for chemical attack of tooth enamel as the wines have $\mathrm{pH}$ values between 3 - 3.8 [12, 14], while the critical point of enamel solubility is at the $\mathrm{pH}$ value of 5 - 5.7 [15-17].

Softening of the enamel surface is an early manifestation of the corrosion process. Reduced surface hardness or decrease of wear resistance, which accompanies corrosion of the enamel surface by acid beverages can then result in excessive wear of teeth, and can be assessed using a physical measurement such as the hardness test. This effect is relatively fast, as shown by Lupi-Pegurier et al., who observed statistically significant decrease of surface microhardness of human teeth enamel already after $120 \mathrm{~s}$ exposure to red wine in-vitro [13]. A simulation of 10 one-minute episodes of wine tasting followed by scratch testing showed significant differences in both scratch depths and surface roughness due to enamel softening at an early stage of wine tasting [18]. Recent studied of enamel exposed to various organic acids by nanoindentation (such as citric acid at $\mathrm{pH} 3.2$ and 5.5 and acetic acid at $\mathrm{pH}$ 5.5) revealed decreasing hardness and Young's modulus with exposure time, and crack generation along the hydroxyapatite rod boundaries 
due to the exposure of enamel to acidic environments [19]. In the tooth enamel demineralized and significantly softened by corrosion in acetic acid solution at $\mathrm{pH}=3$ only partial remineralization of the softened enamel surface layer can occur through subsequent exposure to saliva in-vitro, and some corrosion-induced defects remain unrepaired. As a result, the nanoindentation elastic modulus shows some improvement following remineralization, but hardness does not [20]. The results imply that long term or repeated exposure to corrosive liquids can result in gradual accumulation of corrosioninduced damage. The wear mechanism of enamel was also found to change, from brittle fracture in intact enamel, to ploughing or shaving of the surface layer softened in acidic environments, generating a smooth surface with the progression of wear. [19, 21].

Biological and chemical factors in the oral environment influence the progress of dental corrosion. Saliva provides protective effects by neutralizing and clearing the acid. Saliva is also a source of inorganic ions, such as calcium and phosphate ions, which are the building blocks necessary for the remineralization process [22]. The degree of saturation of these ions differs from person to person, among various salivary glands, and with secretion rate. The dissolution and precipitation of tooth minerals depends on the $\mathrm{pH}$ and the concentrations of ions in the fluid phase surrounding the tooth structures [23]. For patients experiencing dry mouth, saliva substitutes are therefore often prescribed. One of the saliva substitutes available as an over-the-counter product is Biotene ${ }^{\mathbb{B}}$ Mouthwash (GlaxoSmithKline, USA). According to the manufacturer, the mouthwash contains calcium, xylitol, lactoferrin, and enzymes naturally found in human saliva to provide antibacterial protection [24].

Suppression of tooth corrosion is possible also by proper mouth hygiene, with the use of fluorine-containing toothpastes and mouthwashes. It is well established that fluoride ions in the fluid phase surrounding the tooth structures shift the equilibrium in buccal cavity towards re-mineralization. Fluorides enhance re-mineralization of early carious lesions by adsorbing onto the partially dissolved crystal lattice, attracting calcium and phosphate ions to precipitate in the form of crystalline or amorphous calcium phosphate [25]. The amorphous calcium phosphate is biologically active, and is able to release calcium and phosphate ions to maintain the supersaturated state, thus enhancing the remineralization process.

Among the most commonly used mouthwash agents are those produced by Elmex (GABA International AG, Switzerland). Due to its surface activity and slightly acidic $\mathrm{pH}$, amine fluoride present in the mouthwash promotes the formation of calcium fluoride globules. These act as a fluoride deposit, which, according to the producer's data, both protects the teeth against acid attacks and stimulates re-mineralization, providing protection from dentine caries [26]. Except of $\mathrm{CaF}_{2}$, also $\mathrm{NaF}$ and other fluorides, e.g. $\mathrm{TiF}_{4}$, and $\mathrm{NH}_{4} \mathrm{~F}$ were reported to have the protective effect, and are used as a source of fluoride ions in commercially produced toothpastes and mouthwashes [27-29].

The purpose of this study was to evaluate the effect of the early stages of corrosion in a white wine $(\mathrm{pH} 3.5)$ on the hardness of human teeth enamel, evaluated through determination of microhardness of corroded enamel. The protective and remineralization capacity of the commercial mouthwash (Elmex, $\mathrm{pH} 4.4$ ) and of the moisturising mouthwash containing triple enzyme system found in natural saliva, thereinafter referred to as the oral rinse (Biotene ${ }^{\circledR}, \mathrm{pH}$ 5.3), was also evaluated, in terms of change of Vickers hardness of the teeth treated by the two agents before and after exposure to white wine.

\section{EXPERIMENTAL}

Decontamination of intact caries-free human molars extracted due to orthodontic reasons (27 specimens of teeth in total were tested, originating from individuals of either gender and various age) was performed by immersion the teeth into $3 \%$ hydrogen peroxide solution for $5 \mathrm{~s}[13,30,31]$ in order to minimize the risk of transmission of blood-borne pathogens [32], and stored in deionized water at the temperature of $\sim 5^{\circ} \mathrm{C}$ $[30,31]$. The specimens were embedded in a synthetic resin (Dentacryl/ VersoCit-2 Liquid) so that the lateral surfaces, which are most commonly affected by corrosion, were exposed. The exposed surfaces were ground and polished (Buehler Ecomet300/Automet 300) to $0.5 \mu \mathrm{m}$ finish. A care was taken to remove not more than $1 \mathrm{~mm}$ of enamel, in order to avoid exposure of softer, and corrosion less resistant, dentine. After polishing, the specimens were stored in deionized water. Immediately before the corrosion tests the specimens were rinsed with alcohol to dry the exposed surface.

The surface hardness of enamel specimens was measured using a microhardness tester (WIKI 200) with a Vickers diamond indenter under a load of $200 \mathrm{gf}$ $(1.961 \mathrm{~N})$ with $5 \mathrm{~s}$ dwell at the maximum load. Ten indents were carried out for each specimen. The load was selected because it provided the appropriate size of indentations for accurate measurement with the available equipment without disturbing the measured values by excessive crack formation. The baseline surface microhardness before further corrosion/recovery treatment was determined for each specimen.

The corrosion tests were conducted in vitro, using white wine (Pinot Blanc, year 2012, wine region Modra, Slovak Republic, $\mathrm{pH}$ 3.5) as the corroding agent. The polished enamel surface was exposed to $100 \mu \mathrm{l}$ of white wine for 10, 20, 40 and 60 minutes in a climatic chamber (Angelantoni Discovery DY110) at $37^{\circ} \mathrm{C}$ and $95 \%$ relative humidity. The high relative humidity was 
applied in order to prevent evaporation of the solution from the tooth surface. After each exposure time the microhardness was determined.

The mouthwash Elmex $(\mathrm{pH}=4.4)$ was tested for its capacity to influence the microhardness of the enamel, and to protect human teeth against corrosion. For that purpose three un-corroded specimens in parallel were individually exposed to $100 \mu$ l of the mouthwash for 10 , 20, 40 and 60 minutes in the climatic chamber under the same conditions as above, and microhardness was determined after every exposure. The specimen exposed to the mouthwash for 60 minutes was then corroded in the white wine for $10,20,40$ and 60 minutes at $37^{\circ} \mathrm{C}$, and the microhardness was determined.

Both the mouthwash Elmex, and the oral rinse Biotene (pH 5.3) were tested for their capacity to recover the mechanical properties of human teeth enamel after corrosion. The specimens corroded for 60 minutes in white wine were exposed to the moutwash/oral rinse in the same manner as described above, and the recovery of mechanical properties was examined by microhardness testing. Before the tests the $\mathrm{pH}$ value of all used liquids was determined using the $\mathrm{pH}$ meter $\left(\mathrm{pH} 720\right.$, inoLab $\left.{ }^{\circledR}\right)$.

The surfaces of un-corroded, wine corroded, and mouthwash/oral rinse treated surfaces were examined by scanning electron microscopy (JEOL JSM-7600 F) and compositional analysis was carried out by SEMEDS. For SEM imaging all samples were gold sputter coated using a JEOL JFC-1300 „AUTO Sputter Coater“.

\section{RESULTS}

The baseline microhardness of all nine tested tooth specimens showed only a slight variation, which fell well into the range of the scatter of experimental data, and ranged around $340 \pm 7$ HV0.2. The dependences of microhardness as a function of exposure time to the used liquid agents are summarized in Figure 1. Figure 1a shows the decrease of hardness of polished surfaces of two different teeth after various time of exposure to white wine at $37^{\circ} \mathrm{C}$. Despite the fact the tooth samples originated from two different individuals, the influence of corrosion on hardness was comparable. After $60 \mathrm{mi}-$ nutes exposure to white wine the decrease of hardness was considerable, falling down to $190 \mathrm{HV} 0.2$, which represented $45 \%$ decrease in comparison to un-corroded enamel. Figure $1 \mathrm{~b}$ and $\mathrm{c}$ shows the influence of the exposure of enamel corroded 60 minutes in white wine to the fluorine-containing mouthwash and to oral rinse, respectively. In both cases extended exposure to the liquids led to gradual increase of surface hardness of the enamel. The effect was more pronounced if the fluorinating mouthwash was applied, with the hardness recovering back, and even slightly exceeding its original value (> 360 HV0.2). The oral rinse was less efficient, but some hardness recovery was still observable, achieving $320 \mathrm{HV} 0.2$ after 60 minutes exposure.

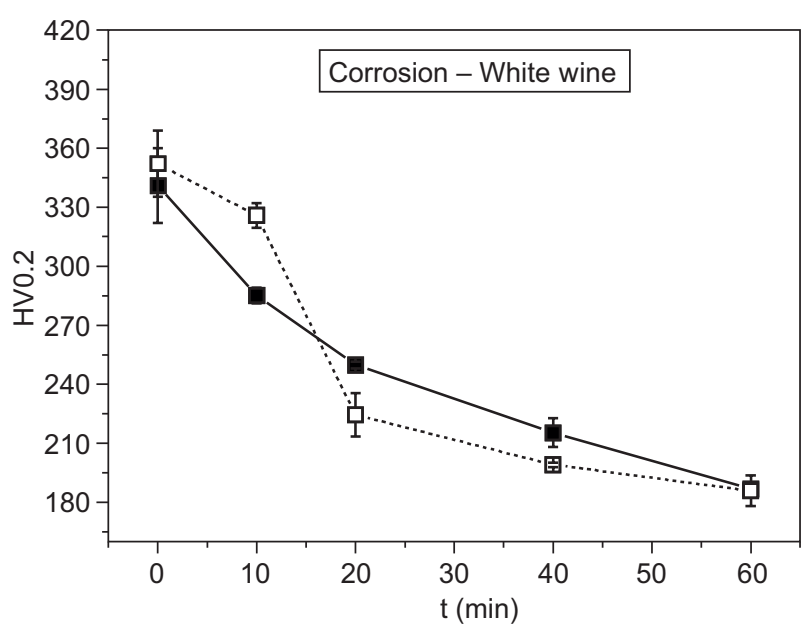

a)

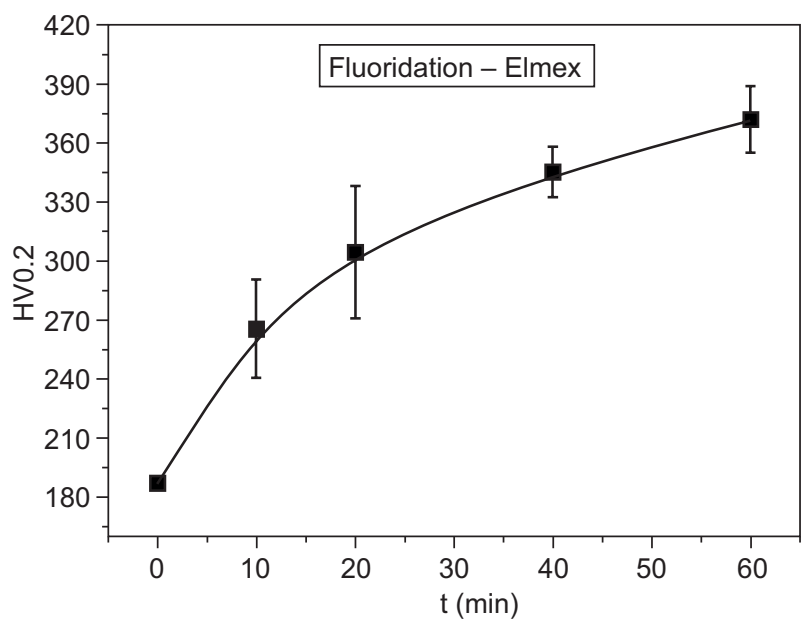

b)

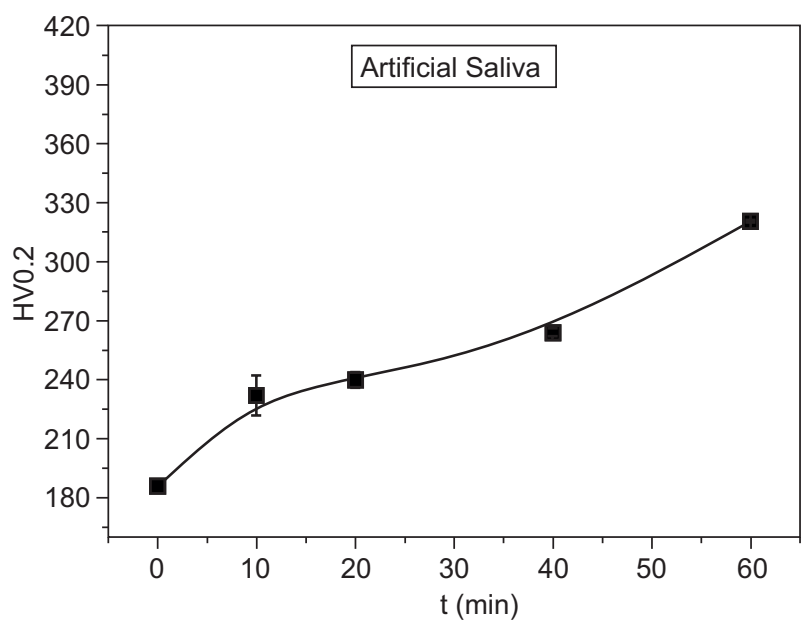

c)

Figure 1. Variation of enamel surface microhardness as a function of the exposure time; a) corrosion of the untreated enamel from 2 different teeth with white wine, b) recovery of surface hardness after 60 minutes corrosion by fluoridation in the mouthwash, c) recovery of surface hardness after 60 minutes corrosion by treatment in the oral rinse. 
The application of the mouthwash had also positive effect on hardness of un-corroded teeth. The exposure to the mouthwash resulted in the increase of hardness of enamel from the original value $350 \mathrm{HV} 0.2$ to $390 \mathrm{HV} 0.2$ after 60 minutes of the test (Figure 2a). The results also indicate that the fluorination protects the enamel surface against the corrosion attack by white wine. The exposure of fluorinated enamel to white wine solution also led to gradual decrease of hardness, which after 60 minutes at $37^{\circ} \mathrm{C}$ dropped to $290 \mathrm{HV} 0.2$ (Figure 2b). However, this represented only $25 \%$ decrease in comparison to the fluorinated un-corroded surface and only $17 \%$ decrease in comparison to the hardness of polished enamel before the treatment.

The SEM micrographs of polished, corroded, and mouthwash or oral rinse treated surfaces of human enamel after corrosion are shown in Figure 3. The polished surface in Figure 3a shows typical features characteristic for enamel samples, e.g. regular rounded crosssections of hydroxyapatite (HAP) rods. The surface is homogeneous and contains nearly no pores or defects. The micrograph shown in Figure $3 b$ represents an enamel surface corroded in white wine for 40 minutes at $37^{\circ} \mathrm{C}$. The influence of corrosion is obvious. The hydroxyapatite rods are difficult to recognize, and the material contains numerous micrometre-sized pores as the result of selective dissolution of hydroxyapatite at the places with lowest durability, i.e. at the interfaces between individual rods. The corroded surface treated with oral rinse enriched besides the enzymes also with calcium ions, shows some features, which indicate healing of the surface as the result of deposition of new mineral phases (Figure 3c). The porosity was reduced, and the hydroxyapatite rods could be clearly distinguished again as the result of topotaxial growth of new mineral phases at the end of HAP rods. The corroded surface treated by the fluorinating mouthwash (Figure 3d) also showed some distinct features.

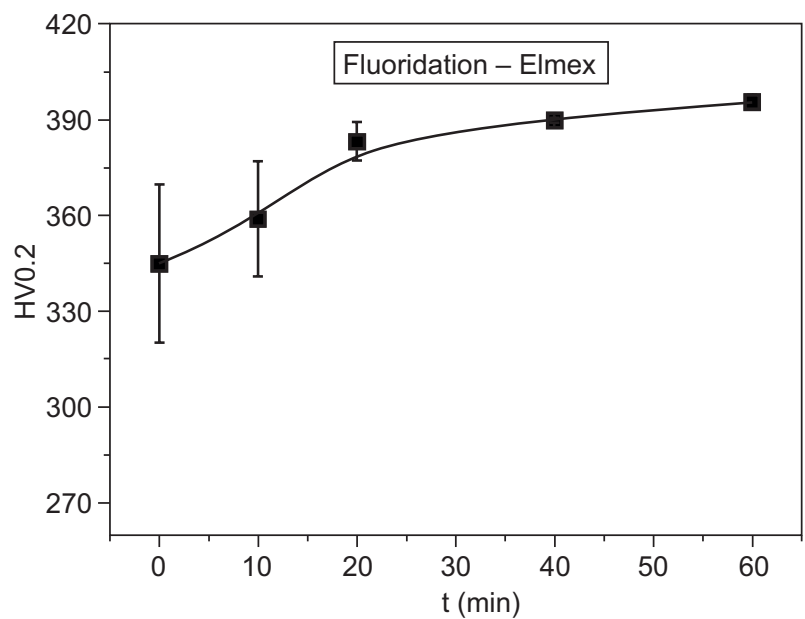

a)
First, the micrometer-sized pores all disappeared, and the HAP rods (although still clearly recognizable) were covered with a thin homogeneous layer of a new phase. Apart from that, the micrographs revealed numerous globular precipitates, about $2.1 \pm 0.1 \mu \mathrm{m}$ in diameter, firmly attached to the surface. Similar features were observed also at the surfaces treated with the mouthwash prior to corrosion (Figure 4a). The surfaces were covered with a homogeneous layer of a new phase, so that the HAP rods were hard to distinguish. The number of precipitates attached to the surface was high, but the precipitates were smaller (approx. $1.3 \pm 0.2 \mu \mathrm{m}$ ) than those found at the surface treated with the mouthwash after corrosion. The polished surface without any distinguished corrosion related features, such as edges or pores, favoured homogeneous deposition of the layer of mineral products, and longer time was needed to create the nuclei with critical size required for the formation and growth of globules. The fluorinated surface after 40 minutes exposure in the white wine is shown in Figure $4 \mathrm{~b}$. The HAP rods were easy to distinguish, and the number of globules decreased dramatically. The diameter of the remaining globules dropped to $0.6 \pm 0.1 \mu \mathrm{m}$, as the result of their dissolution. The surface mineral layer almost entirely dissolved in the corrosion agent.

The changes in concentrations of calcium, phosphorus, and fluorine, as the main mineral components of human enamel in the course of demineralization and re-mineralization were monitored by SEM/EDS. Characteristic $\mathrm{Ca}$ and $\mathrm{P}$ contents in un-corroded enamel were $25.5 \pm 1.4$ at. $\%$ and $15.2 \pm 0.7$ at. \%, respectively, which corresponds to the $\mathrm{Ca} / \mathrm{P}$ ratio of 1.67 characteristic for mineral hydroxyapatite. The content of fluorine was at the level of the detection limit of the method. The results of EDS analysis of the enamel treated prior to corrosion by the fluorine-containing mouthwash are summarized in the Table 1. The analysed areas are outlined and numbered in Figure 5. The enamel treated

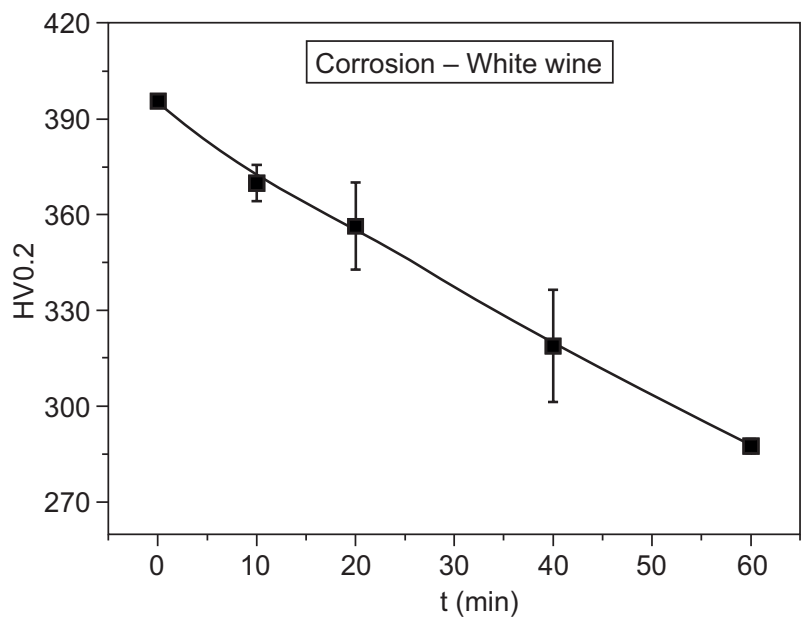

b)

Figure 2. Variation of enamel surface microhardness as a func-tion of the exposure time; a) Increase of hardness of human enamel by fluoridation in the mouthwash, b) Decrease of hardness of fluorinated tooth by corrosion in white wine. 


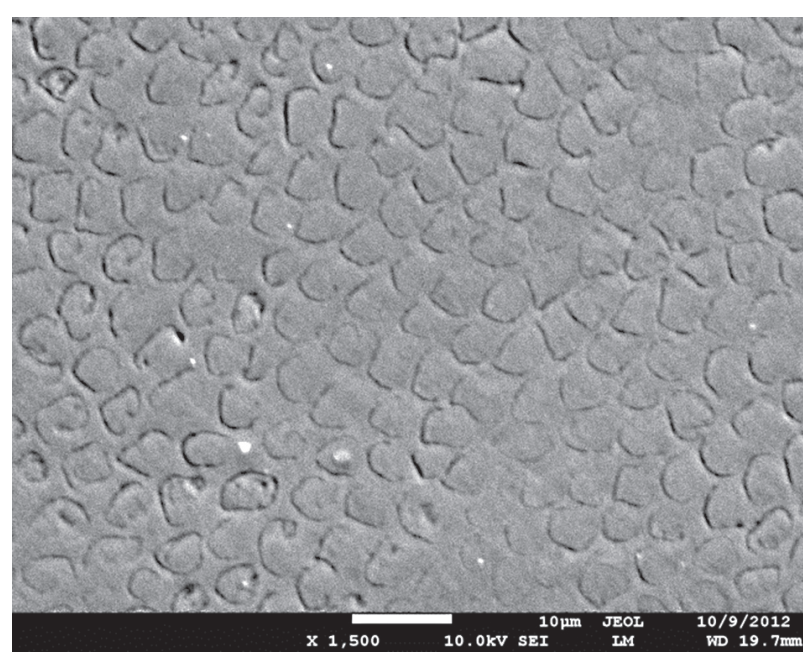

a)

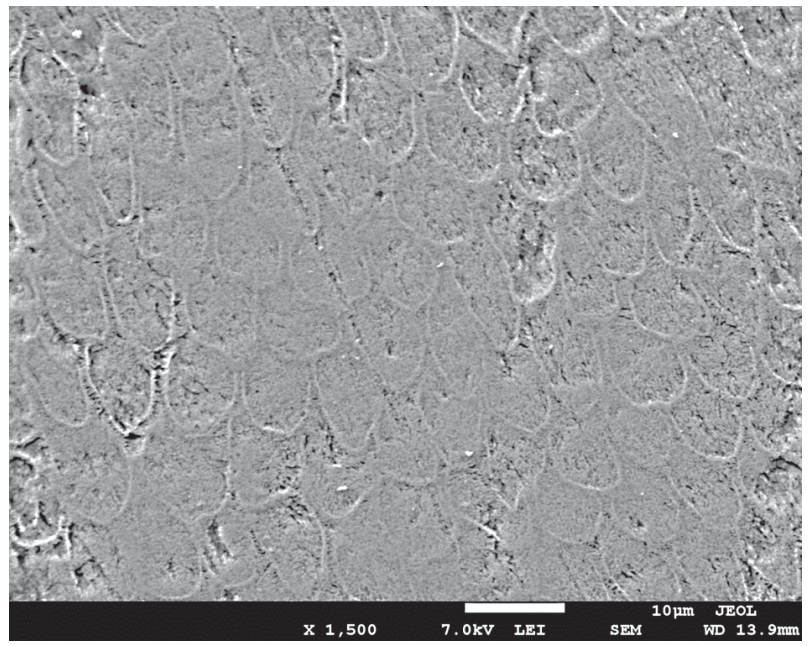

c)

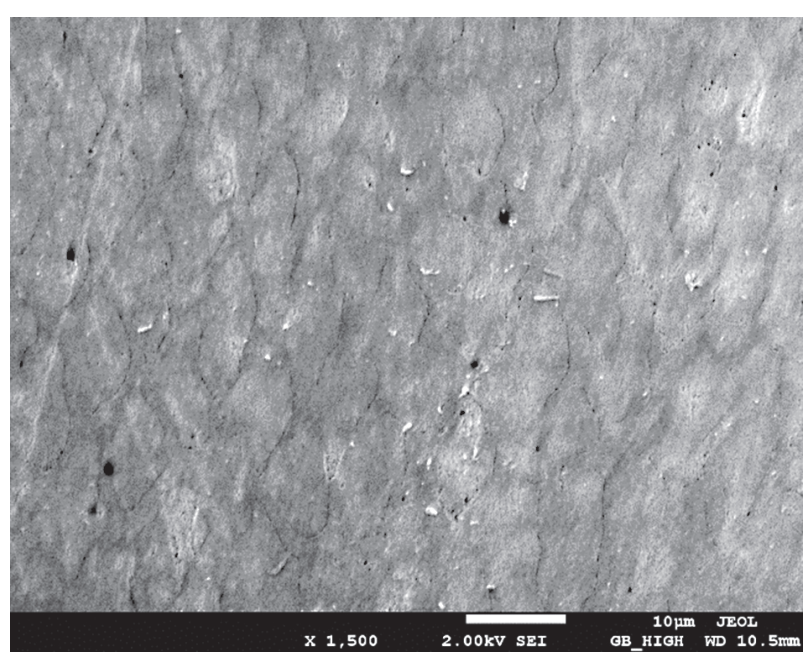

b)

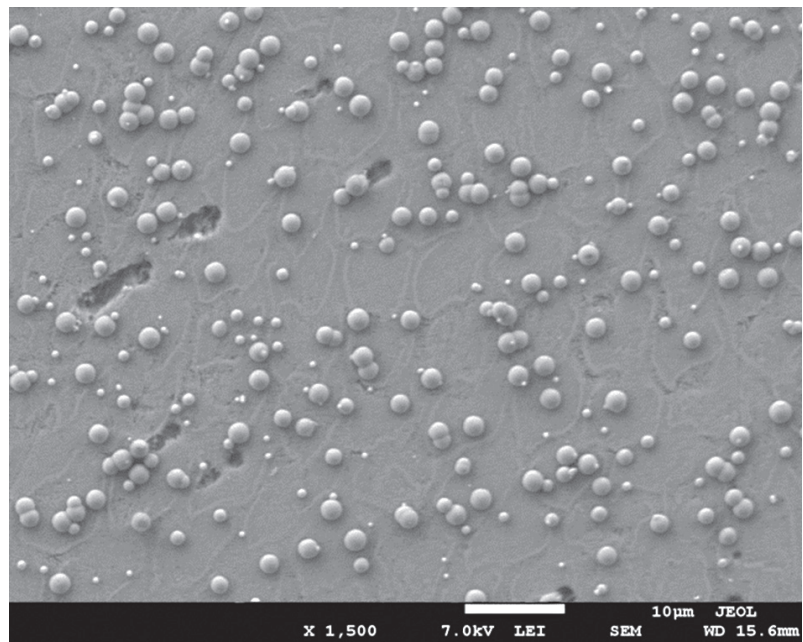

d)

Figure 3. Scanning electron micrographs of human enamel: a) uncorroded surface after polishing, b) polished surface corroded for $40 \mathrm{~min}$ at $37^{\circ} \mathrm{C}$ in white wine, c) corroded surface after $40 \mathrm{~min}$ exposure to Biotene oral rinse, d) corroded surface after $40 \mathrm{~min}$ exposure to Elmex Mouthwash.

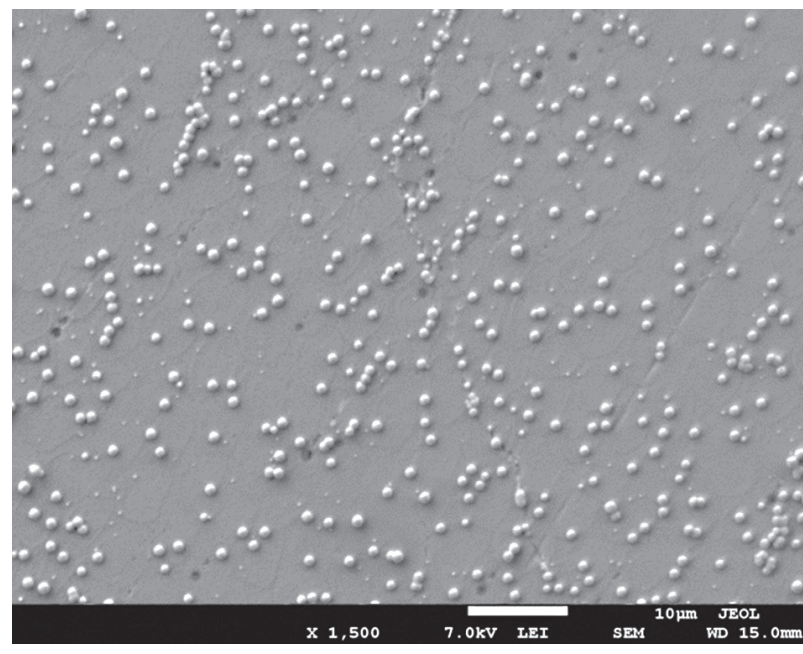

a)

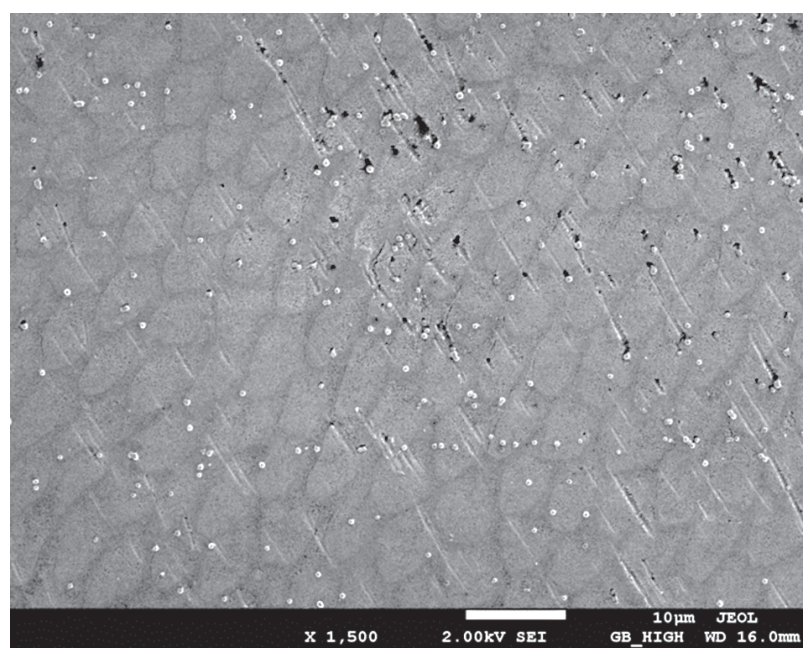

b)

Figure 4. Scanning electron micrographs of human enamel: a) uncorroded surface after 40 min exposure to Elmex Mouthwash b) Elmex treated surface after $40 \mathrm{~min}$ corrosion at $37^{\circ} \mathrm{C}$ in white wine. 
before corrosion with the mouthwash contained increased amounts of $\mathrm{Ca}(35 \pm 2$ at. $\%)$ and $\mathrm{P}(19 \pm 2$ at.\%). Markedly increased content of fluorine (9 \pm 2 at.\%) was also detected in the mouthwash treated enamel, suggesting incorporation of fluorine into newly created mineral phase(s). The content of $\mathrm{F}$ in the globular precipitates formed at the enamel surface as the result of mouthwash treatment was markedly higher (up to $47 \pm 4$ at.\%), with correspondingly lower contents of $\mathrm{Ca}(23 \pm 1$ at. \%), $\mathrm{P}(5.6 \pm 1.1$ at. $\%)$ and oxygen $(22 \pm 3$ at.\%). The results of EDS analysis indicate that treatment with fluorinecontaining mouthwash results in precipitation of $\mathrm{CaF}_{2}$ at enamel surface, as suggested by the $\mathrm{F} / \mathrm{Ca}$ atomic ratio close to 2. The apparent content of other elements $(\mathrm{P}$, $\mathrm{O}$, etc.) is the result of penetration of electron beam into underlying substrate. Subsequent exposure of the mouthwash treated teeth in white wine resulted in nearly complete dissolution of precipitated calcium fluoride.

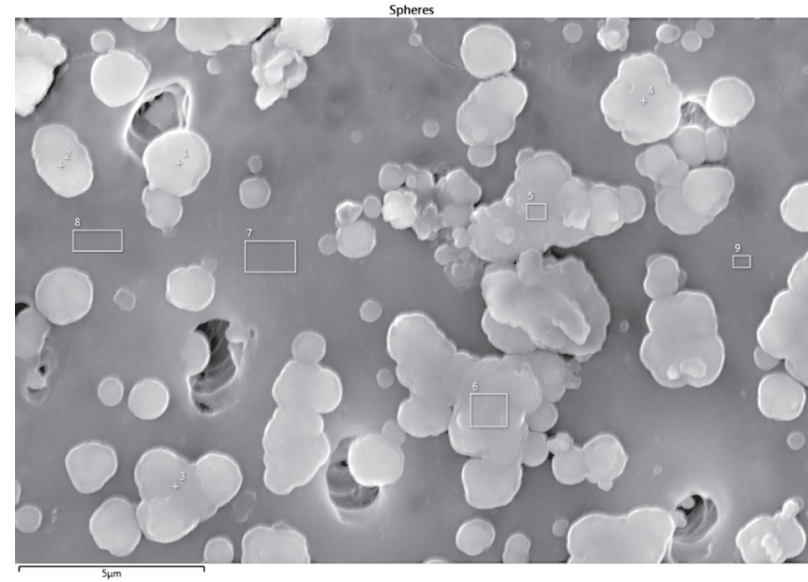

Figure 5. Scanning electron micrographs/ Energy dispersive spectroscopy: globular precipitates on the uncorroded surface exposure to Elmex Mouthwash. The rectangular areas outline the places where the surface was analysed by EDS (Table 1).

\section{DISCUSSION}

Except of surface demineralization by bacterial acids excessive consumption of acidic food and beverages is one of the most common factors that cause dental corrosion. The damage caused by alcoholic beverages like white wines is found mainly in special occupational groups like wine makers and wine tasters, but also in chronic alcoholics, where a prolonged contact of teeth with the wine is linked to tooth corrosion [31]. Mineral components of teeth, especially calcium and phosphorus, are released from the teeth enamel. Formation of cracks, pores and cavities can be also observed. However, the extent of corrosion caused by alcoholic beverages like white wines is usually far smaller than in the case of non-alcoholic carbonated drinks or fruit juices. This is attributed to two factors. First, wine usually does not contain any citric acid, which has strong chelating activity towards calcium, shifting the reaction equilibrium of HAP dissolution towards dissolved reaction products. Second, wine itself usually contains relatively high concentrations of calcium and phosphate ions, so that the corrosion solution is quickly saturated and re-precipitation of new apatite phases HAP at the corroded surface can be observed. Relatively high concentrations of $\mathrm{Ca}\left(78 \pm 3 \mathrm{mg}^{-l^{-1}}\right)$ and phosphates $\left(221 \pm 6 \mathrm{mg} \cdot \mathrm{l}^{-1}\right)$ were determined by ICP OES in the white wine used as a corrosion medium in this work. Despite this fact, marked influence of the exposure to white wine on micromechanical surface properties of enamel was observed. These results are in accord with extensive in vitro studies, clearly showing significant corrosive potential of various wines in terms of enamel demineralisation and release of calcium [31], as well as the clinical studies, which clearly show serious damage of human teeth by cumulative action of demineralization and excessive abrasion of enamel, likely related to

Table 1. The results of EDS chemical analysis (at. \%) of uncorroded enamel after treatment with fluorine containing mouthwash. The analyzed areas are outlined by rectangles and numbered in Figure 5. Symbol s represents the standard deviation of the analyzed value.

\begin{tabular}{ccccccccccc}
\hline $\begin{array}{c}\text { Analysed } \\
\text { area }\end{array}$ & $\mathrm{O}$ & $\mathrm{F}$ & $\mathrm{Na}$ & $\mathrm{Mg}$ & $\mathrm{Al}$ & $\mathrm{Si}$ & $\mathrm{P}$ & $\mathrm{S}$ & $\mathrm{Ca}$ & Total \\
\cline { 2 - 11 } & \multicolumn{7}{c}{ Globular precipitates } \\
\hline 1 & 20.5 & 49.6 & 1.1 & 1.6 & 0.6 & 0.0 & 4.6 & 0.2 & 21.8 & 100.0 \\
2 & 22.8 & 46.3 & 1.2 & 1.6 & 0.5 & 0.0 & 5.1 & 0.2 & 22.4 & 100.0 \\
3 & 24.0 & 44.6 & 1.2 & 1.5 & 0.5 & 0.0 & 6.6 & 0.2 & 21.4 & 100.0 \\
4 & 20.1 & 45.9 & 1.0 & 1.5 & 0.5 & 0.0 & 6.6 & 0.2 & 24.2 & 100.0 \\
5 & 25.6 & 40.9 & 1.1 & 1.4 & 0.6 & 0.2 & 6.6 & 0.3 & 23.4 & 100.0 \\
6 & 16.9 & 51.0 & 1.1 & 1.7 & 0.6 & 0.0 & 4.4 & 0.2 & 24.1 & 100.0 \\
\hline Mean & 21.6 & 46.4 & 1.1 & 1.6 & 0.6 & 0.0 & 5.6 & 0.2 & 22.9 & \\
s & 3.1 & 3.6 & 0.1 & 0.1 & 0.1 & 0.1 & 1.1 & 0.0 & 1.2 & \\
\hline & & & & & Smooth surface & & & & \\
\hline 7 & 37.4 & 6.6 & 1.0 & 1.0 & 0.0 & 0.0 & 19.5 & 0.4 & 34.1 & 100.0 \\
8 & 37.4 & 11.0 & 1.0 & 1.0 & 0.1 & 0.0 & 17.4 & 0.5 & 31.6 & 100.0 \\
9 & 32.8 & 8.2 & 0.9 & 1.1 & 0.0 & 0.0 & 20.3 & 0.6 & 36.0 & 100.0 \\
\hline Mean & 35.8 & 8.6 & 1.0 & 1.0 & 0.0 & 0.0 & 19.1 & 0.5 & 33.9 & 100.0 \\
s & 2.7 & 2.2 & 0.0 & 0.1 & 0.1 & 0.0 & 1.5 & 0.1 & 2.2 & 0.0 \\
\hline
\end{tabular}


hardness decrease as the result of demineralization as the critical $\mathrm{pH}$ value is exceeded [33]. Interestingly, LupiPegurier et al. who measured the surface hardness of human enamel after prolonged exposure to wine suggest that the exposure to wine is innocuous for an immersion time of less than $120 \mathrm{~s}$ in vitro. [13]. However, their work does not take into account possible accumulation of corrosion damage after extended and repeated exposure of enamel to corrosive media. In the present study we therefore applied longer exposure times ranging from 10 to 60 minutes, with regular influx of fresh corrosion medium in defined time intervals in order to eliminate possible saturation of the medium with products of HAP dissolution, particularly $\mathrm{Ca}$ and phosphate ions. The arrangement of the experiment thus simulated extended exposition and cumulative effect of the exposure to acidic environment. The results show remarkable decrease of microhardness of dental enamel already after 10 minutes exposure to white wine. The damage becomes more pronounced with prolonged exposure (decrease from 347 HV0.2 in pristine enamel to $186 \mathrm{HV} 0.2$ after 60 minutes exposure at $37^{\circ} \mathrm{C}$ ). Apart from decrease of microhardness the Vickers hardness measurements revealed also different behaviour of indented surfaces in terms of their response to indentation after the exposure to white wine. In the pristine, un-corroded samples, the indentation was always accompanied by formation of radial cracks originating in the corners of the residual imprint (Figure $6 a$ ) and, in some cases, microcraks in the close vicinity of the indent, following intergranular path among HAP rods (in the figure marked by arrows). The corroded samples exhibited purely plastic behaviour with virtually no cracking (Figure 6b), only exceptionally accompanied by development of lateral cracks and chipping of surface enamel layer adjacent to the indent. Higher extent of plastic deformation was explained by demineralization of the enamel surface, complete removal of the mineral hydroxyapatite, and related increase of the content of

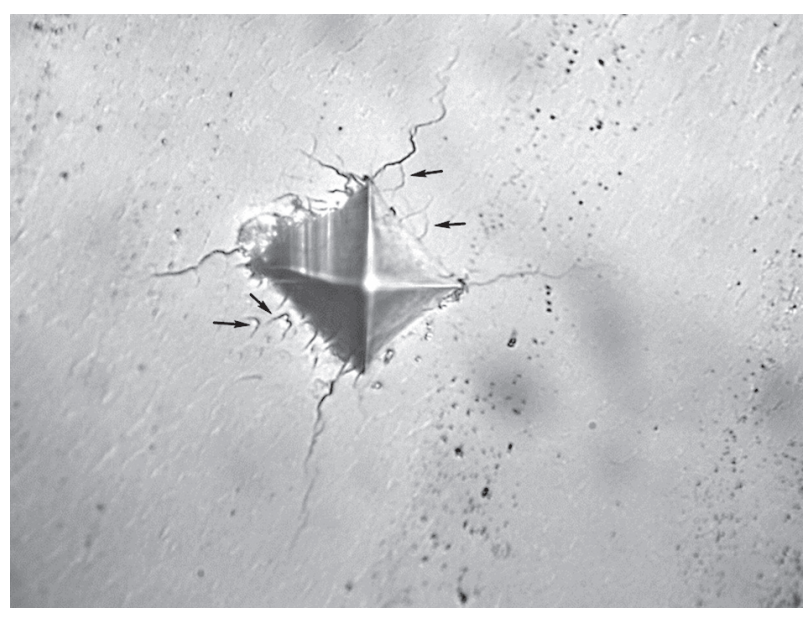

a) organic component of the enamel. The SEM imaging confirmed serious damage of enamel surface as the result of corrosive action of white wine (Figure $3 b$ ). The surface contained numerous micrometer-sized pores as the result of selective dissolution of hydroxyapatite at the places with the lowest durability, i.e. at the interfaces between individual HAP rods.

In terms of corrosion protection, saliva has a strong buffering capacity, which helps to neutralize the action of acids and increases the $\mathrm{pH}$ in buccal cavity [25]. If production of saliva is insufficient (dry mouth symptoms), corrosive potential of acid drinks is enhanced. Additional protection by artificial means is then often advertised, e.g. by mouthwashes often referred to as "moisturizing relief or stimulation products". Objective evaluation of the corrosion protection action of a selected commercial product was one of the goals of this work. The moutwash Biotene ${ }^{\mathbb{B}}$ was selected for the purpose of this study because it contains protein and enzymatic components that are not available in other common saliva-like solutions. Casein phosphopeptide component of the moutwash stabilizes amorphous calcium phosphate at the enamel surface and binds onto adsorbed macromolecules of biofilm on the tooth surface where it serves as a reservoir for calcium and phosphate ions [34]. Clinical studies also found that Biotene ${ }^{\mathbb{B}}$ mouthwash, toothpaste, and chewing gum relieve the symptoms of xerostomia (dry mouth syndrome) in head and neck cancer patients [35]. However, Tantbirojn et al. observed negative influence of a long term exposure $(24 \mathrm{~h}$ and $48 \mathrm{~h}$ ) of the Biotene ${ }^{\mathbb{B}}$ oral rinse on the surface hardness of bovine enamel [24]. The authors attribute the effect to several factors, including removal of the original enamel surface by polishing during sample preparation, lack of saliva in the experiment, which could buffer the action of Biotene (it should be kept in mind that the $\mathrm{pH}$ value of Biotene was determined to be $5.297 \pm 0.003$, which is below the critical threshold for HAP dissolution), and the

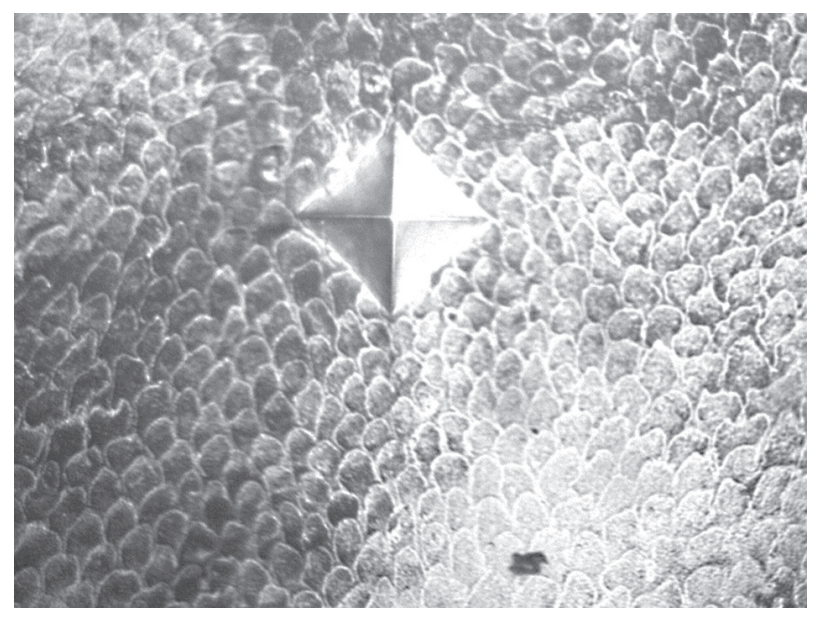

b)

Figure 6. Vickers hardness indentations: a) uncorroded surface after polishing, b) polished surface corroded for 40 min at $37^{\circ} \mathrm{C}$ in white wine. 
fact that bovine, instead of human enamel was used for the study. Other authors also report that artificial caries lesions formed in bovine tooth enamel were twice as deep as those formed in human teeth [36]. Our experiments indicate positive influence of the Biotene ${ }^{\mathbb{B}}$ oral rinse on microhardness of corroded human enamel after short term exposure (maximum 60 minutes) to white wine. The hardness of enamel increased from $186 \mathrm{HV} 0.2$ in corroded enamel to $320 \mathrm{HV} 0.2$ after 60 minutes treatment in Biotene ${ }^{\circledR}$ at $37^{\circ} \mathrm{C}$. The treated surface shows creation of new mineral phases of similar chemical composition as the original, un-corroded surface. The hydroxyapatite rods could be again clearly distinguished and porosity was reduced after the Biotene ${ }^{\circledR}$ treatment as the result of topotaxial growth of newly formed apatite mineral phases at the end of HAP rods.

The mouthwash Elmex was selected for the experiment as one of the most frequently used fluorinated over-the-counter products. According to the producer's data the mouthwash contains olaflur (amine fluoride) and sodium fluoride $(0.025 \% \mathrm{~F})$, which activates formation of a protective film at dental necks, increasing the caries protection. The application of the mouthwash on polished un-corroded surfaces resulted in a measurable hardness increase from the original $350 \mathrm{HV} 0.2$ to $390 \mathrm{HV} 0.2$ after 60 minutes exposure (Figure 2a). The surface of treated enamel was covered with a homogeneous layer of a new, Ca-, P- and F-containing phase. Fluorine was detected both in the surface layer, and in the globular precipitates attached to the enamel's surface. The content of fluorine in the surface layer $(8.6 \pm 2.2$ at. \%) suggests fluoroapatite formed by incorporation of fluorine into the structure of hydroxyapatite or a mixture of fluoroapatite with calcium fluoride are the main components of the precipitated layer. High contents of both calcium and fluorine (46 \pm 4 at. \%) and the $\mathrm{F} / \mathrm{Ca}$ atomic ratio close to 2 in globular precipitates identify them as calcium fluoride. The hardness of corroded human enamel increased after treatment with the mouthwash from 186 HV0.2 to $372 \mathrm{HV} 0.2$ after 60 minutes exposure at $37^{\circ} \mathrm{C}$.

The mechanism of action of fluorine on mechanical properties - especially hardness - of enamel (and hydroxyapatite in general) is not quite clear. Literature survey reveals that the $\mathrm{F}$ content in enamel typically ranges between 0.01 and 0.07 wt. \% [37-40]. The results of studies of mechanical properties of sintered HAP and F-substituted HAP obtained from natural or artificial sources are ambiguous. They generally show decrease of hardness with increasing $\mathrm{F}$ content [41]. However, $\mathrm{F}$ was found to impair sintering of hydroxyapatite, with resulting higher porosity of the sintered material. Decrease of hardness can be thus attributed to lower relative density of sintered materials, not to structural changes of HAP caused by incorporation of fluorine. Another study concluded that the hardness remains unaffected until $80 \%$ replacement of hydroxyl groups with fluoride ions, after which the hardness increases rapidly. The elastic modulus increases linearly with the content of fluoride anions. Fluoride incorporation enhanced fracture toughness, which reached a peak of $1.8 \mathrm{MPa} \cdot \mathrm{m}^{1 / 2}$ for a $95 \%$ dense sintered pellet with $60 \%$ of hydroxyl groups replaced by fluoride anions [42]. Mechanisms of the increase of hardness of human teeth enamel observed in this study cannot be thus directly related to incorporation of fluorine into the HAP structure or precipitation of F-containing phases. The hardness increase of corroded enamel after its exposure to fluorine-containing mouthwash was rather attributed to precipitation of secondary phases, which filled the surface pores created by the corrosion process, and by the change of the contact area under the indenter due to formation of globular $\mathrm{CaF}_{2}$ precipitates. However, the study confirmed protective action of fluoridation against corrosive effect of white wine. These results are in accord with previously published data, which reported on the protective action of various fluorinecontaining agents (pastes, varnishes or gels) against corrosion induced by coca cola drinks both in primary and permanent teeth $[3,43]$. The protective effect of fluoride is mainly attributed to the formation of a $\mathrm{CaF}_{2}$ like layer on the tooth surface, which acts as a fluoride reservoir. During an acidic attack, fluoride released from the $\mathrm{CaF}_{2}$ deposit can be incorporated into the mineral by forming fluoroapatite or fluorohydroxyapatite resulting in a decreased susceptibility to further dissolution. The $\mathrm{CaF}_{2}$ layer might also act as a mechanical or diffusion barrier preventing the contact of acid with the underlying enamel or as a mineral reservoir which, when attacked by the corrosive medium, releases metallic ions thus leading to a buffering or depletion of hydrogen ions from the acid [44].

\section{CONCLUSIONS}

An in-vitro evaluation of the influence of a selected type of white wine on surface microhardness of human tooth enamel was carried out. The capacity of two different over-the-counter products, the fluorine containing mouthwash Elmex, and the oral rinse Biotene ${ }^{\circledR}$ advertised as the "artificial saliva" in terms of re-mineralisation and recovery of the surface mechanical properties was also tested. The surface hardness decreased markedly with the time of exposure to white wine. The decrease was attributed to dissolution of hydroxyapatite and related demineralization of the enamel. Both the fluorine containing mouthwash and the oral rinse exhibited remarkable capacity in terms of surface re-mineralization, surface hardness recovery and, in the case of the Elmex mouthwash, also the ability to form fluorine containing layer of surface precipitates with protective capacity against corrosion in white wine. 
Acknowledgments

The financial support of this work by the grant VEGA 2/0058/14, and the grant APVV 0218-11 is gratefully acknowledged. This publication was created in the frame of the project "Centre of excellence for ceramics, glass, and silicate materials" ITMS code 262201 20056, based on the Operational Program Research and Development funded from the European Regional Development Fund.

\section{REFERENCES}

1. Attin T., Koidl U., Buchalla W., Schaller H.G., Kielbassa A.M., Hellwig E. (1997): Correlation of microhardness and wear in differently eroded bovine dental enamel, Archives of Oral Biology, 42, 243-250. doi:10.1016/00039969(06)00073-2

2. Eisenburger M., Shellis R.P., Addy M. (2003): Comparative study of wear of enamel induced by alternating and simultaneous combinations of abrasion and erosion in vitro, Caries Research, 37, 450-455. doi:10.1159/000073399

3. Badr S.B.Y., M. Ibrahim A. (2010): Protective effect of three different fluoride pretreatments on artificially induced dental erosion in primary and permanent teeth, Journal of American Science, 6, 442-451.

4. Lussi A., Jaeggi T., Schaffner M. (2002): Diet and dental erosion, Nutrition, 18, 780-781.

5. Jarvinen V.K., Rytomaa I.I., Heinonen O.P. (1991): Risk factors in dental erosion, Journal of Dental Research, 70, 942-947. doi:10.1177/00220345910700060601

6. Barbour M.E., Parker D.M., Allen G.C., Jandt K.D. (2003): Human enamel dissolution in citric acid as a function of $\mathrm{pH}$ in the range $2.30 \leq \mathrm{pH} \leq 6.30$ : A nanoindentation study, European Journal of Oral Sciences, 111, 258-262. doi:10.1034/j.1600-0722.2003.00039.x.

7. Bartlett D. (2005): The implication of laboratory research on tooth wear and erosion. Oral Diseases, 11, 3-6. doi:10.1111/j.1601-0825.2004.01063.x

8. Beiraghi S., Atkins S., Rosen S., Wilson S., Odom J., Beck M. (1989): Effect of calcium lactate in erosion and S. mutans in rats when added to Coca-Cola, Pediatric Dental Journal, 11, 312-315.

9. Grando L.J., Tames D.R., Carsoso A.C., Gabilan N.H. (1996): In vitro study of enamel erosion caused by soft drinks and lemon juice in deciduous teeth analysed by stereomicroscopy and scanning electron microscopy, Caries Research, 30, 373-378. doi: 10.1159/000262347

10. Featherstone J.D.B., Lussi A. (2006): Understanding the chemistry of dental erosion, Monographs in Oral Science, 20, 66-76. doi: 10.1159/000359943

11. Mok T.B., McIntyre J., Hunt D. (2001): Dental erosion: In vitro model of wine assessor's erosion, Australian Dental Journal, 46, 263-268. doi: 10.1111/j.1834-7819.2001. tb00290.x

12. Gray A., Ferguson M.M., Wall J.G. (1998): Wine tasting and dental erosion. Case report, Australian Dental Journal, 43, 32-34. doi: 10.1111/j.1834-7819.1998.tb00149.x

13. Lupi-Pegurier L., Muller M., Leforestier E., Bertrand M.F., Boll M. (2003): In vitro action of Bordeaux red wine on the microhardness of human dental enamel, Archives of Oral Biology, 48, 141-145. doi:10.1016/S0003-9969(02)00206-6

14. Wiktorsson A.M., Zimmerman M., Angmar-Mansson B. (1997): Erosive tooth wear: prevalence and severity in
Swedish winetasters, European Journal of Oral Sciences, 105, 544-550. doi:10.1111/j.1600-0722.1997.tb00215.x

15. Touyz L.Z. (1994): The acidity (pH) and buffering capacity of Canadian fruit juice and dental implications, Journal of the Canadian Dental Association, 60, 454-458.

16. Ferguson M.M., Dunbar R.J., Smith J.A., Wall J.G. (1996): Enamel erosion related to winemaking, Occupational Medicine (Lond,) 46, 159-162.

17. Meurman J.H., ten Cate J.M. (1996): Pathogenesis and modifying factors of dental erosion, Europenal Journal of Oral Science, 104, 199-206. doi:10.1111/j.1600-0722.1996. tb00068.x

18. Kwek S.X.R., Mian M., Hall C., Xie Z., Yong R., Kaidonis J., Townsend G.C., Ranjitkar S. (2015): Nanoscratch testing for the assessment of enamel demineralization under conditions simulating wine erosion, Australian Dental Journal, 60, 12-17. doi:10.1111/adj.12277

19. Zhang Y., Arsecularatne J.A., Hoffman M. (2015): The effects of three different food acids on the attrition-corrosion wear of human dental enamel, Journal of Physics D-Applied Physics, 48, 285401. doi:10.1088/0022-3727/48/ 28/285401

20. Arsecularatne J.A., Hoffman M. (2014): An in vitro study of the microstructure, composition and nanoindentation mechanical properties of remineralizing human dental enamel, Journal of Physics D-Applied Physics, 47, 315403. doi:10.1088/0022-3727/47/31/315403

21. Wu Y.Q., Arsecularatne J.A., Hoffman M. (2015): Effect of acidity upon attrition-corrosion of human dental enamel, Journal of The Mechanical Behavior of Biomedical Materials, 44, 23-34. doi:10.1016/j.jmbbm.2014.12.016

22. Zero D.T., Lussi A. (2005): Erosion-chemical and biological factor of importance to the dental practitioner, International Dental Journal, 55, 285-290. doi:10.1111/j.1875595X.2005.tb00066.x

23. ten Cate B. (2004): The role of saliva in mineral equilibriacaries, erosion and calculus formation, in: Edgar M, Dawes C, O'Mullane D, (Ed.). Saliva and Oral Health. 3rd ed. BDJ Books, London: BDJ Books, pp. 120-135.

24. Tantbirojn D., Huang A., Ericson M.D., Poolthong S. (2008): Change in surface hardness of enamel by a cola drink and a CPP-ACP paste, Journal of Dentistry, 36, 74-79. doi:10.1016/j.jdent.2007.10.008

25. Featherstone J.D.C. (2000): The science and practice of caries prevention, Journal of the American Dental Association, 131, 887-899. doi:10.14219/jada.archive.2000. 0307

26. http://www.gaba.com/htm/568/en/Products.htm?Brand= elmexSensitive \&Product=17877: $(29.2 .2014)$

27. Ireland A.J., McGuinness N., Sherriff M. (1995): An investigation into the ability of soft drinks to adhere to enamel, Caries Researech, 29, 470-476. doi:10.1159/000262117

28. Jarvinen V.K., Rytomaa I.I., Heinonen O.P. (1991): Risk factors in dental erosion, Journal of Dental Research, 70, 942-947. doi: 10.1177/00220345910700060601

29. Lussi A., Schaffner M., (2000): Progression of and risk factors for dental erosion and wedge- shaped defects over a 6-year period, Caries Research, 34, 182-187. doi:10.1159/ 000016587

30. Mok T. B., McIntyre J., Hunt D. (2001): Dental erosion: In vitro model of wine assessor's erosion, Australian Dental Journal, 46, 263-268. doi:10.1111/j.1834-7819.2001. tb00290.x 
31. Willershausen B., Callaway A., Azrak B., Kloß Ch., SchulzDobrick B. (2009): Prolonged in vitro exposure to white wines enhances the erosive damage on human permanent teeth compared with red wines, Nutrition Research, 29, 558-567. doi:10.1016/j.nutres.2009.08.004

32. Lolayekar N. V., Bhat V. S., Bhat S. S. (2007): Disinfection methods of extracted human teeth, Journal of Oral Health \& Community Dentistry, 1, 27-29.

33. Sajewicz E. (2007): Tribological behaviour of human enamel in red wine and apple juice environments, Wear, 262, 308-315. doi:10.1016/j.wear.2006.05.010

34. Reynolds E.C., Cai F., Shen P., Walker G.D. (2003): Retention in plaque and remineralization of enamel lesions by various forms of calcium in a mouthrinse or sugar-free chewing gum, Journal of Dental Research, 82, 206-211. doi:10.1177/154405910308200311

35. Warde P., Kroll B., O‘Sullivan B., Aslandidis J., TewGeorge E., Waldron J. (2000): A phase II study of Biotene in the treatment of postradiation xerostomia in patients with head and neck cancer, Support Care Cancer, 8, 203-208. doi:10.1007/s005200050286

36. Edmunds D.H., Whittaker D.K., Green R.M. (1988): Suitability of human, bovine, equine, and ovine tooth enamel for studies of artificial bacterial carious lesions, Caries Research, 22, 327-336. doi:10.1159/000261132

37. Murugan R., Kumar T.S., Rao K.P. (2002): Fluorinated bovine hydroxyapatite: preparation and characterization, Materials Letters, 57, 429-433. doi:10.1016/S0167577X(02)00805-4

38. Oktar F.N., Kesenci K., Piskin E. (1999): Characterization of processed tooth hydroxyapatite for potential biomedical implant applications, International Journal of Artifficial Cells, Blood Substitution Immobilisation Biotechnology, 27, 367-379. doi:10.3109/10731199909117706

39. Schemehorn B.R., Orban J.C., Wood G.D., Fischer G.M., Winston A.E. (1999): Remineralization by fluoride enhanced with calcium and phosphate ingredients, Journal of Clinical Dentistry, 10, 13-16.

40. Mahoney E.K., Rohanizadeh R., Ismail F.S.M., Kilpatrick N.M., Swain M.V. (2004): Mechanical properties and microstructure of hypomineralised enamel of permanent teeth, Biomaterials, 25, 5091-5100. doi:10.1016/j.biomaterials.2004.02.044

41. Gross K. A., Bhadang K. A. (2004): Sintered hydroxyfluorapatites. Part III: Sintering and resultant mechanical properties of sintered blends of hydroxyapatite and fluorapatite, Biomaterials, 25, 1395-1405. doi:10.1016/j.biomaterials.2003.08.051

42. Gross K.A., Rodriguez-Lorenzo L. M. (2004): Sintered hydroxyfluorapatites. Part II: Mechanical properties of solid solutions determined by microindentation, Biomaterials, 25, 1385-1394. doi:10.1016/S0142-9612(03)00636-7

43. Hooper S.M., Newcombe R.G., Faller R., Eversole S., Addy M., West N.X. (2007): The protective effects of toothpaste against erosion by orange juice: Studies in situ and in vitro, Journal of Dentistry, 35, 476-481. doi:10.1016/j. jdent.2007.01.003

44. Saxegaard E., Rolla G. (1988): Fluoride acquisition on and in human enamel during topical application in vitro. Scandinavian Journal of Dental Research, 96, 523-535. doi:10.1111/j.1600-0722.1988.tb01592.x 